\title{
Amount Recovered from T1 to T2 Normalized by Surface Area
}

National Cancer Institute

\section{Source}

National Cancer Institute. Amount Recovered from T1 to T2 Normalized by Surface

Area. NCI Thesaurus. Code C102361.

The cumulative amount recovered from the specimen type specified in PPSPEC over the interval from $\mathrm{T} 1$ to $\mathrm{T} 2$ divided by surface area. 